Obere Extremität 2019 · 14:263-268 https://doi.org/10.1007/s11678-019-00544-1 Received: 7 July 2019

Accepted: 23 September 2019

Published online: 29 October 2019

(c) The Author(s) 2019

\section{Introduction}

Elbow stiffness usually occurs after elbow trauma. Depending on the patient's requirements, even a small loss of motion can lead to severe functional limitations of the elbow joint. These limitations may substantially reduce the patient's quality of life. If conservative treatment does not provide a satisfying result, arthrolysis of the stiff elbow can be performed either arthroscopically or by an open approach aiming to relieve pain relating to mechanical symptoms and impingement and to recover a functional range of motion $(\mathrm{ROM})[3,8]$. Although satisfactory outcomes are reported in retrospective comparative studies and case series for both procedures, there is a paucity of direct prospective comparisons of the two techniques $[3,9]$.

Hence, the aim of the study was to analyze the clinical short-term results of arthroscopic and open elbow arthrolysis in postoperative and posttraumatic stiff elbows.

\section{Methods}

A total of 126 patients treated with elbow arthrolysis were enrolled in this prospective study. The indication for surgery was elbow stiffness resistant to conservative medical treatment over a minimum of 3 months. Patients that received additional hardware removal during surgery or other additional surgical procedures (for example, ligament reconstruction due to inherent instability), as well as patients with incomplete post-

T. Leschinger (D) - M. Hackl · M. Lenz · V. Rausch · L. P. Müller · K. Wegmann

Center for Orthopedic and Trauma Surgery, University Medical Center, Cologne, Germany

\title{
A prospective comparison of short-term results after arthroscopic and open elbow procedures in elbow stiffness
}

operative evaluation forms during the defined follow-up times, were excluded. After application of these criteria, 44 patients could be included in the study population.

Group 1 included patients receiving arthroscopic arthrolysis. It consisted of 18 (54.4\%) women and $15(27.6 \%)$ men, with an average age of 45.5 years (range, 19-72 years).

Group 2 included patients after open arthrolysis and consisted of four (36.4\%) women and seven (64.4\%) men, with an average age of 38.6 years (range, $19-67$ years). Previous surgery was performed in 13 patients $(43.3 \%)$ in the arthroscopic group (four arthroscopic procedures, nine open procedures) and seven patients $(63.4 \%)$ in the open group (six open procedures, one arthroscopic procedure).

Demographic characteristics are presented in - Table 1. Patients were evaluated preoperatively for age, sex, dominant limb, pain score (numerical rating scale; NRS), ROM in extension and flexion, as well as disabilities of the arm, shoulder, and hand (DASH) score.

The operative techniques for open and arthroscopic procedures have previously been described in detail $[5,8]$. In addition to the standard arthroscopic procedure, seven patients in this group underwent ulnar nerve decompression.

After surgery, the patients were clinically examined in a standardized fashion including the clinical outcomes by using DASH score, NRS, and ROM (extension/ flexion) 6 weeks, 3 months, and 6 months after surgery. Furthermore, the question of whether patients would opt for this surgery again was reviewed.

\section{Postoperative management}

Postoperative management was identical for both cohorts. In particular, postoperative progressive active motion was allowed after day 1 , which was encouraged under the instruction of a clinical physician. An additional temporary splinting (Mayo orthosis, DJO Global, Vista, CA, USA) was applied for the first 2-4 weeks to increase and maintain ROM in extension and flexion.

\section{Statistical analysis}

The empirical distribution of the parameters defining clinical outcome in this study was described by tabulation of the mean, standard deviation, minimum, and maximum. The Mann-Whitney $\mathrm{U}$ test was performed to analyze the variables in the two groups. A twotailed $p$ value of $<0.05$ was considered significant. All analyses were performed in SPSS 23 (IBM Inc., Armonk, NY).

Approval was obtained from our institutional review board.

\section{Results}

In the arthroscopic group, the preoperative ROM arc improved significantly from $103.3^{\circ}( \pm 23.4)$ to $116.3^{\circ}\left( \pm 15.5^{\circ} ; p=0.01\right)$ after 6 weeks and increased to $120.9^{\circ}$ $\left( \pm 15.1^{\circ} ; p=0.001\right)$ after 3 months and $123.5^{\circ}\left( \pm 12.5^{\circ} ; p=0.001\right)$ after 6 months. In the group receiving open arthrolysis, 
Table 1 Demographic characteristics of the two groups

\begin{tabular}{|c|c|c|c|}
\hline & Arthroscopic & Open & $p$-Value \\
\hline Age (years) & $45.55( \pm 14.63)$ & $38.82( \pm 15.41)$ & \multirow[t]{2}{*}{-} \\
\hline Sex & $\begin{array}{l}18(54.4 \%) \text { Women, } \\
15(27.6 \%) \text { men }\end{array}$ & $\begin{array}{l}4(36.4 \%) \text { Women, } \\
7(64.4 \%) \text { men }\end{array}$ & \\
\hline Previous surgery & $13 / 33(43.3 \%)$ & $7 / 11$ (63.4\%) & - \\
\hline ROM (extension/flexion) & $103.3^{\circ}\left( \pm 23.4^{\circ}\right)$ & $64.5^{\circ}\left( \pm 31.1^{\circ}\right)$ & 0.001 \\
\hline NRS & $5.5( \pm 2.5)$ & $4.6( \pm 2.8)$ & 0.38 \\
\hline DASH & $37.3( \pm 23.4)$ & $38.2( \pm 24.1)$ & 0.27 \\
\hline Dominant limb & 25/33 (83.3\%) & $6 / 11(54.5)$ & - \\
\hline
\end{tabular}

Table 2 Delta values compared to preoperative status. Comparison of both groups

\begin{tabular}{llll}
\hline Delta values compared to preoperative & Arthroscopic & Open & p-Value \\
\hline ROM & & & \\
\hline 6 Weeks & $12.9( \pm 21.9)$ & $28.6( \pm 23.5)$ & 0.13 \\
\hline 3 Months & $18.9( \pm 20.9)$ & $33.6( \pm 17.7)$ & 0.68 \\
\hline 6 Months & $21.3( \pm 21.3)$ & $36.8( \pm 29.6)$ & 0.98 \\
\hline VAS & & & \\
\hline 6 Weeks & $-2.4( \pm 2.2)$ & $-0.89( \pm 3.5)$ & 0.24 \\
\hline 3 Months & $-2.7( \pm 2.7)$ & $-1.63( \pm 3.2)$ & 0.31 \\
\hline 6 Months & $-3.1( \pm 3.0)$ & $-2.0( \pm 2.9)$ & 0.32 \\
\hline $\begin{array}{l}\text { DASH } \\
6 \text { Weeks }\end{array}$ & $-3.9( \pm 27.2)$ & $-2.7( \pm 20.9)$ & 0.85 \\
\hline 3 Months & $-16.5( \pm 26.0)$ & $-14.5( \pm 30.9)$ & 0.67 \\
\hline 6 Months & $-22.3( \pm 21.6)$ & $-21.0( \pm 26.9)$ & 0.69 \\
\hline $\begin{array}{l}\text { ROM range of motion in extension and flexion, } \text { VAS visual analogue scale, DASH disabilities of the } \\
\text { arm, shoulder and hand }\end{array}$ & & \\
\hline
\end{tabular}

the mean ROM arc also increased significantly from $64.5^{\circ}\left( \pm 31.1^{\circ}\right)$ to $93.2^{\circ}$ $( \pm 21.7 ; p=0.028)$ after 6 weeks, $98.2^{\circ}$ $\left( \pm 21.6^{\circ}, p=0.015\right)$ after 3 months and $100.9^{\circ}\left( \pm 25.6^{\circ}, p=0.007\right)$ after 6 months (• Fig. 1). The gain in elbow motion between the two groups showed no significant differences compared to preoperative values ( $p>0.05$; $\bullet$ Table 2$)$.

In the arthroscopic group, the mean DASH score was 37.3 points $( \pm 23.4$ points) preoperatively, improving to 29.7 points $( \pm 23.3$ points, $p=0.16)$ after 6 weeks, 21.1 points $( \pm 20.9$ points; $p=0.005)$ after 3 months, and 16.1 points $( \pm 16.5$ points, $p=0.001)$ after 6 months. In the open arthrolysis group, the DASH score improved postoperatively compared to its preoperative value by 38.2 points ( \pm 24.1 points). A score of 35.4 points $( \pm 16.2$ points, $p=0.76)$ was recorded after 6 weeks, 28.9 points ( \pm 24.3 points, $p=0.52$ ) after 3 months, and 19.45 points $( \pm 17.5$ points, $p=0.02)$ after 6 months (• Fig. 2).

Similarly, the NRS decreased after surgery in both groups. However, only in the arthroscopic group did the reduction of pain showed statistical significance. In the arthroscopic group, the NRS decreased from 5.5 points ( \pm 2.5 points) preoperatively to 3.1 points $( \pm 2.7, p=0.002)$ after 6 weeks, and from 2.9 points $( \pm 2.6$ points, $p=0.001)$ after 3 months to 2.3 points $( \pm 2.3$ points, $p=0.001)$ after 6 months. Comparably, the NRS dropped in the open group from 4.6 points ( \pm 2.8 points) to 3.7 points $( \pm 1.9$ points; $p=0.34) 6$ weeks postoperatively, 3.0 points $( \pm 2.4$ points, $p=0.30$ ) after 3 months, and 2.6 points $( \pm 2.4$ points; $p=0.15)$ after 6 months (- Fig. 3).

When comparing the delta values of the groups between the preoperative ROM, DASH score, and NRS, no sig- nificant changes could be seen $(p>0.05$; - Table 2).

After 6 months, 32 patients (96\%) in the arthroscopic group and all patients in the open group stated that they would opt for the respective surgery again. Neurovascular complications and infections did not occur in either group.

\section{Discussion}

The present prospective study analyzed the clinical short-term results of arthroscopic and open elbow arthrolysis. The outcome was evaluated using the range of elbow motion, pain on an NRS, and the DASH score. Both techniques resulted in satisfactory to excellent functional recovery in the cohorts presented here. This is supported by the finding after 6 months that 32 patients (96\%) in the arthroscopic group and all 11 patients in the open group indicated that they would opt for the respective surgery again. Significant improvements in elbow motion were found in both cohorts compared to preoperative values. After 6 months, the mean increase in ROM in the open group reached $36^{\circ}$, whereas the arthroscopic group recorded an increase of $21^{\circ}$. The improvement in elbow motion between the two groups showed no significant differences. However, a tendency towards a higher improvement in elbow motion in the open group is in line with a previous systematic review that reported a higher increase in ROM in studies evaluating the outcomes after open procedures (mean ROM $52^{\circ}$ ) compared to the arthroscopic series (mean ROM 40 ${ }^{\circ}$ [6]. This might be due to the fact that, in the authors' department, open arthrolysis is predominantly performed in elbows with a larger restriction of motion (open group mean ROM $64.5^{\circ}$ vs. arthroscopic group mean ROM $103.3^{\circ}$ ). Large intrinsic components are managed by a more aggressive approach, which allows for releasing the posterior band of the medial collateral ligament (MCL) in order to achieve higher degrees of motion, especially in flexion. Furthermore, these results are supported by a recent retrospective study that reported better outcomes regarding flexion limitation after an open procedure in osteocapsular arthroplasty for primary os- 
Obere Extremität 2019 · 14:263-268 https://doi.org/10.1007/s11678-019-00544-1

(c) The Author(s) 2019

T. Leschinger · M. Hackl · M. Lenz · V. Rausch · L. P. Müller · K. Wegmann

\section{A prospective comparison of short-term results after arthroscopic and open elbow procedures in elbow stiffness}

\section{Abstract}

Background. Surgical treatment of the stiff elbow can be performed either arthroscopically or via an open approach. There is a paucity of direct prospective comparisons of the techniques in the literature.

Objectives. The aim of the study is to analyze the clinical short-term results of arthroscopic and open elbow arthrolysis in postoperative and posttraumatic stiff elbows.

Materials and methods. The study group consisted of 44 patients divided in two cohorts, one after arthroscopic arthrolysis (33 patients) and the other including patients after open arthrolysis (11 patients). Range of motion (ROM; extension/flexion), pain (numerical rating scale, NRS), as well as the disabilities of the arm, shoulder, and hand (DASH) score were recorded preoperatively and examined in a standardized manner
6 weeks, 3 months, and 6 months after surgery.

Results. In both groups, preoperative elbow movement significantly improved in the follow-up. An increase from $103.3^{\circ}( \pm 23.4)$ to $123.5^{\circ}\left( \pm 12.5^{\circ} ; p=0.001\right)$ was seen after 6 months for the arthroscopic group, whereas the mean ROM significantly increased from $64.5^{\circ}\left( \pm 31.1^{\circ}\right)$ to $100.9^{\circ}\left( \pm 25.6^{\circ} ; p=0.007\right)$ following open arthrolysis.

In the arthroscopic group, the DASH score was measured at 37.3 points ( \pm 23.4 points) and improved to 16.1 points ( \pm 16.5 points) after 6 months, while in the open group it enhanced after 6 months ( 19.5 points $[ \pm 17.5$ points]) compared to its preoperative value by 38.2 points ( \pm 24.1 points). A consistent improvement was found for NRS, which decreased after surgery in both groups (arthroscopic group $=-3.1[ \pm 3.0]$; open group $=-2.0[ \pm 2.9])$. Complications did not occur in either group. When comparing delta values of the groups between the preoperative ROM, DASH score, and NRS, no significant differences were observed $(p<0.05)$.

Conclusions. Good to excellent functional recovery was seen in both cohorts when evaluating for improvement in the DASH score, the gain in elbow motion, and the decrease in pain. No significant differences were found between the procedures regarding pre- and postoperative measurements. The arthroscopic approach has developed to become an effective alternative to treat posttraumatic elbow stiffness.

Keywords Arthroscopic arthrolysis . Open arthrolysis . Elbow stiffness - Elbow contracture . Prospective study

\section{Prospektiver Vergleich der kurzfristigen Ergbenisse nach arthroskopischer und offener Arthrolyse von bewegungssteifen Ellenbogen}

\section{Zusammenfassung}

Hintergrund. Die operative Versorgung bewegungssteifer Ellenbogen kann offen oder arthroskopisch erfolgen. Es mangelt an Studiendaten zum direkten prospektiven Vergleich.

Ziel der Arbeit. Ziel der Studie war es, das kurzfristige klinische Outcome nach offener und arthroskopischer Arthrolyse von Ellenbogen mit postoperativer oder posttraumatischer Bewegungseinschränkung zu vergleichen.

Material und Methoden. 44 Patienten wurden prospektiv erfasst und anhand des operativen Vorgehens (offen vs. arthroskopisch) in zwei Gruppen untergliedert; 33 Patienten wurden arthroskopisch versorgt, 11 Patienten mit einer offenen Arthrolyse. Präoperativ sowie zu den Follow-up-Zeitpunkten nach 6 Wochen, 3 Monaten und 6 Monaten wurden der Bewegungsumfang (Extension/Flexion), Schmerz (numerische Rating-Skala) sowie das funktionelle Outcome anhand des DASHScores (Disabilities of the Arm, Shoulder and Hand) standardisiert erhoben.

Ergebnisse. In beiden Gruppen zeigte sich eine signifikante Verbesserung des Bewegungsumfangs. In der arthroskopischen Gruppe stieg die Beweglichkeit von 103,3 $3^{\circ}$ $\left( \pm 23,4^{\circ}\right)$ auf $123,5^{\circ}\left( \pm 12,5^{\circ} ; p=0,001\right)$ nach 6 Monaten, während in der offenen Gruppe eine Verbesserung von $64,5^{\circ}\left( \pm 31,1^{\circ}\right)$ auf $100,9^{\circ}\left( \pm 25,6^{\circ} ; p=0,007\right)$ erzielt wurde. Der DASH-Score verbesserte sich nach 6 Monaten in der arthroskopischen Gruppe von 37,3 $( \pm 23,4)$ auf 16,1 Punkte $( \pm 16,5)$ und in der offenen Gruppe von 38,2 ( $\pm 24,1)$ auf 19,5 Punkte $( \pm 17,5)$. Gleichzeitig fiel das Schmerzempfinden in der arthroskopischen Gruppe um 3,1 Punkte $( \pm 3,0)$ und in der offenen Gruppe um 2,0 Punkte $( \pm 2,9)$. Komplikationen traten in keiner der beiden Gruppen auf. Bei Vergleich der Delta-Werte in Bezug auf den präoperativen Bewegungsumfang, DASHScore und NRS-Wert konnten zwischen dem offen und arthroskopisch versorgten Patientenkollektiv keine signifikanten Unterschiede detektiert werden $(p<0,05)$. Schlussfolgerungen. Beide Kollektive zeigten eine gute bis hervorragende funktionelle Verbesserung in Bezug auf den funktionellen Score, den Bewegungsumfang und die Schmerzlinderung. Signifikante Unterschiede zwischen den Verfahren bezüglich prä- und postoperativer Messwerte konnten nicht ermittelt werden. Das arthroskopische Vorgehen hat sich zu einer effektiven Alternative bei der Versorgung der posttraumatischen Bewegungssteife am Ellenbogen entwickelt.

Schlüsselwörter

Arthroskopische Arthrolyse - Offene Arthrolyse - Bewegungssteifer Ellenbogen . Ellenbogenkontraktur · Prospektive Studie teoarthritis compared to an arthroscopic group after a mean follow-up time of 36.6 months [7]. As discussed in recent literature, additional mini-open ulnar nerve decompression and posterior MCL bundle release could be a promis- ing additional procedure to the arthroscopic approach to increase elbow flexion in cases of severe stiff elbow [7].

Nevertheless, the excellent arc of elbow motion of $123.5^{\circ}$ in the arthroscopic group after a follow-up period of
6 months leads to the conclusion that, in most elbows, arthroscopic osteocapsular release enables fully acceptable exposure for the removal of osseous components, such as ectopic bone and osteophytes, and capsular release. These conclusions 


\section{Originalarbeit}

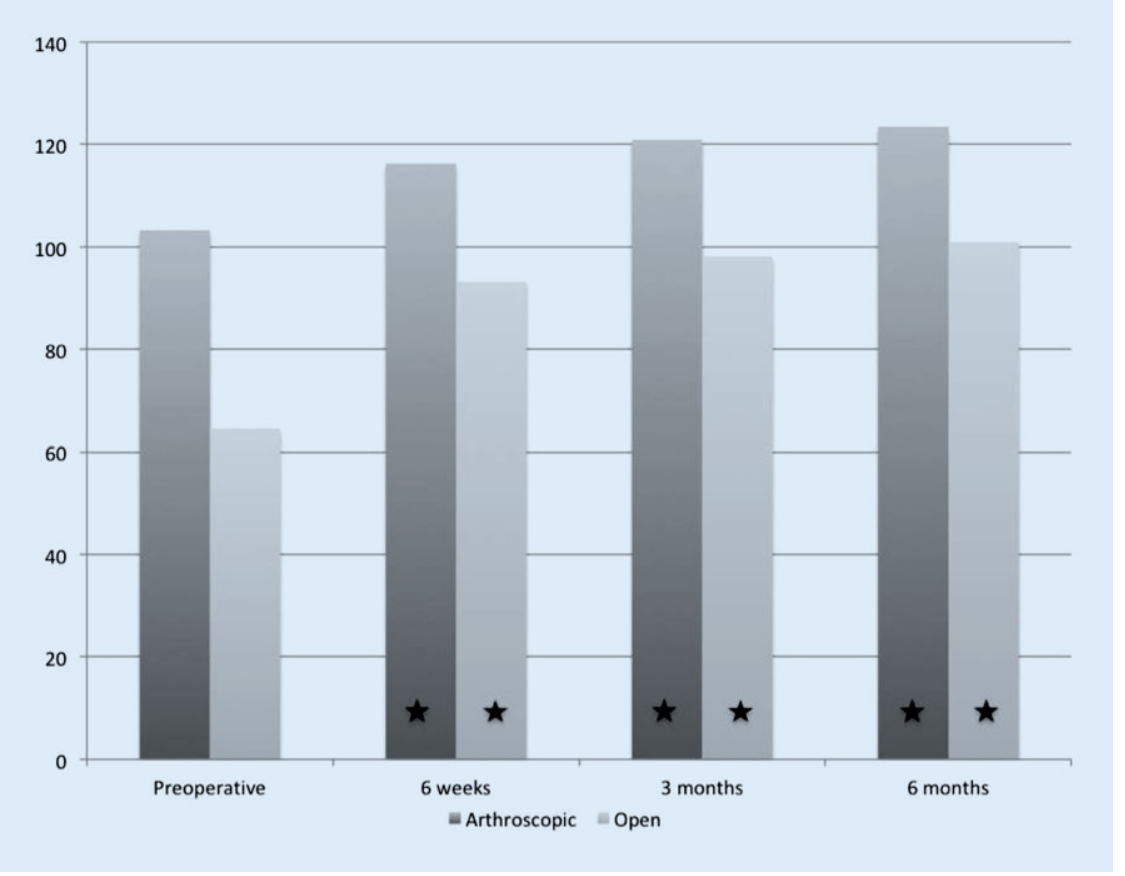

Fig. $1 \Delta$ Preoperative and postoperative range of motion (extension/flexion). Significant differences compared to the preoperative values are marked by blackasterisks

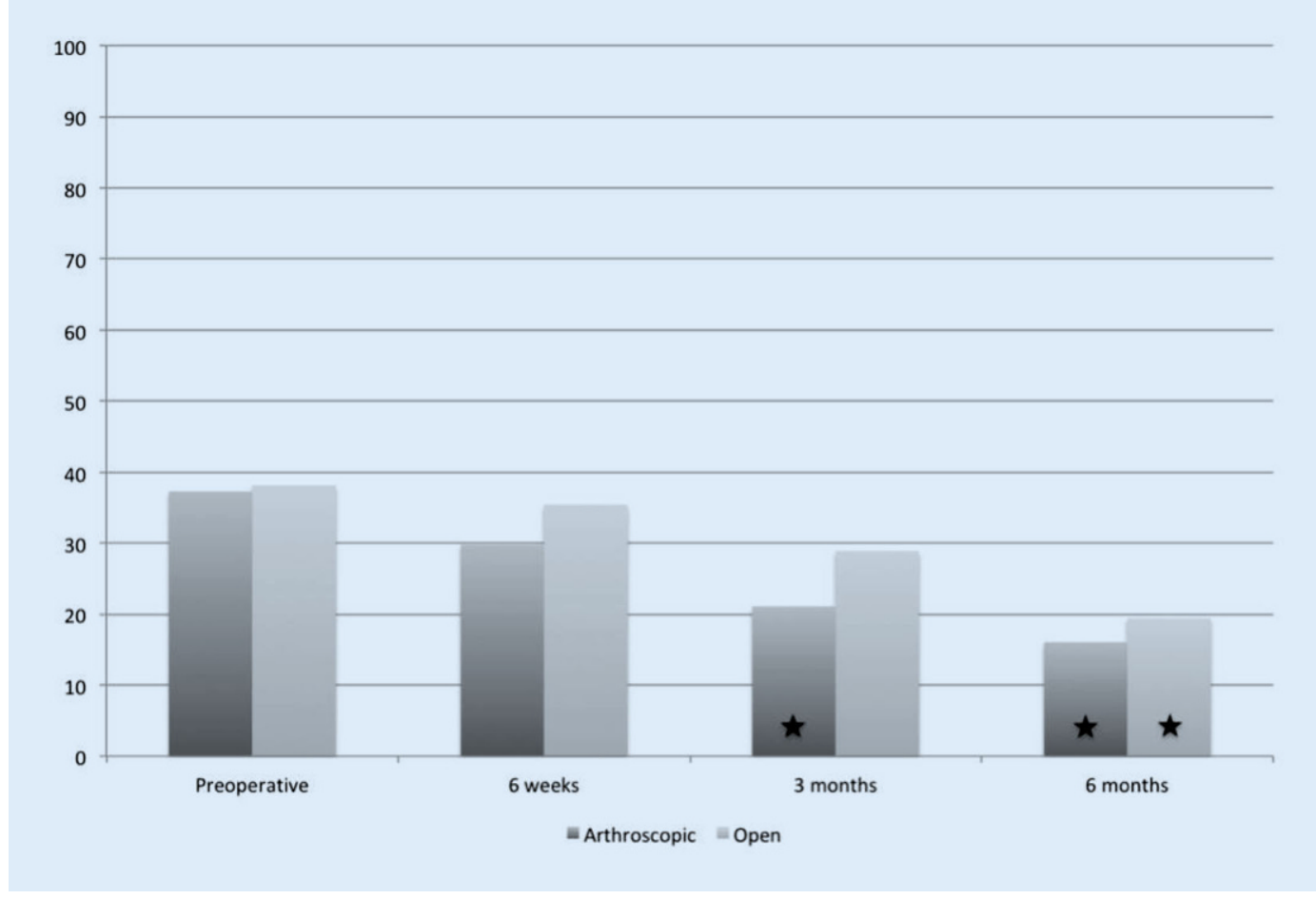

Fig. $2<$ Preoperative and postoperative evaluations of the disabilities of the arm, shoulder, and hand score. Significant differences compared to the preoperative values are marked by black asterisks

are supported by the satisfactory results of the outcome variables of the DASH score and the decrease in pain levels. In the arthroscopic group, the mean DASH score of 37.3 points improved significantly to 16.1 points after 6 months, while the NRS decreased from
5.5 points to 2.3 . These results are supported by several studies reporting the arthroscopic procedure to be effective in patients with posttraumatic elbow contracture [2, 9-13]. However, due to the proximity of neurovascular structures, arthroscopic arthrolysis is a challenging procedure of high technical complexity $[4,8]$. Therefore, the open procedure is considered by several authors to be the standard treatment for managing contracted elbows, especially in elbows with large intrinsic and extrinsic components $[3,6]$. 


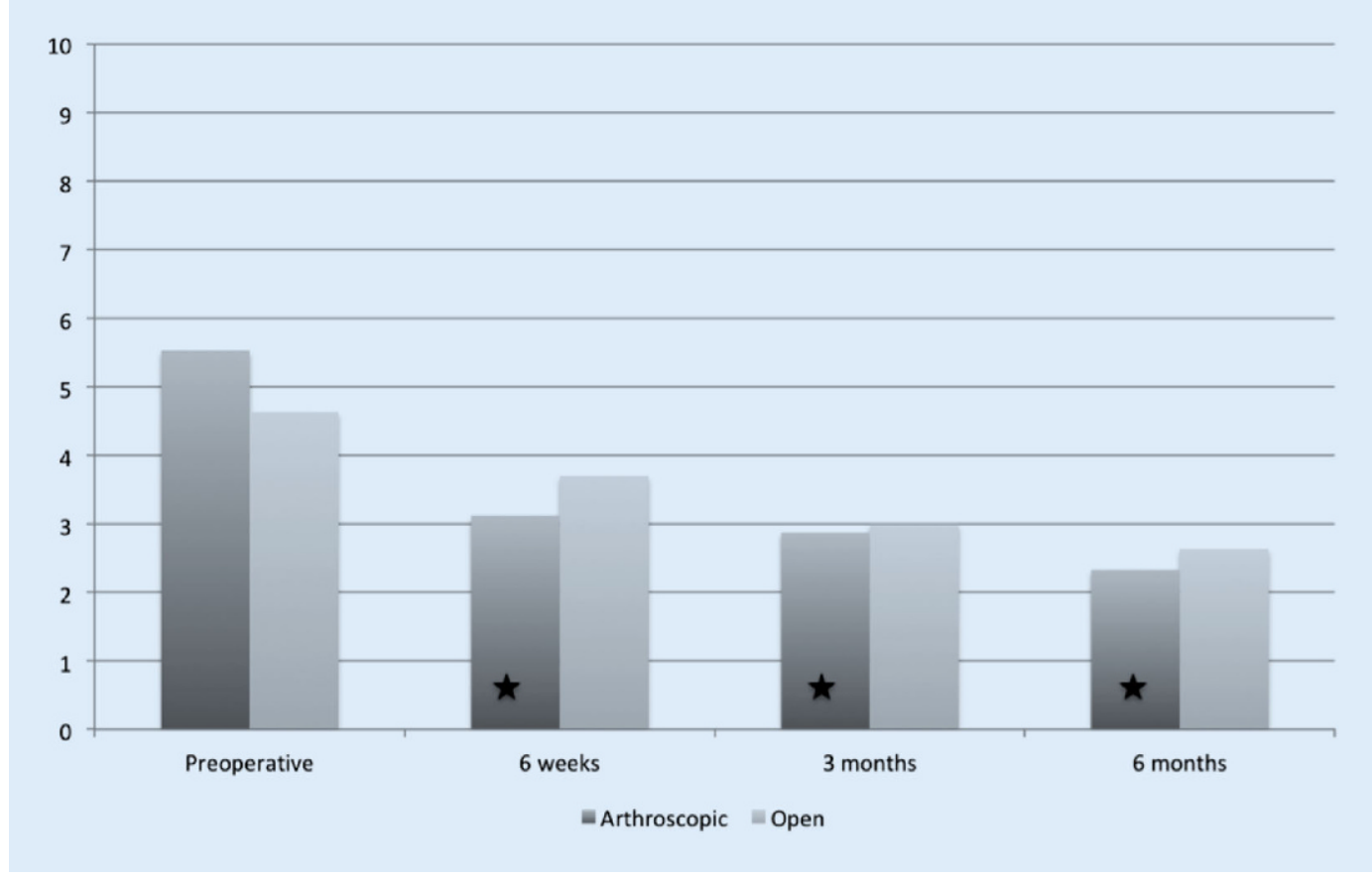

Fig. $3<$ Preoperative and postoperative evaluations of pain (numerical rating scale). Significant differences compared to the preoperative values are marked by black asterisks

Although no complications were observed in either cohort reported here, the literature discusses the volume of complications as rising with the extent of the surgical procedure, which in turn suggests that less invasive procedures are favorable [6]. Therefore, the results presented here strongly support an arthroscopic approach in contracted elbows [1, 6]. The transition to an arthroscopic approach is, in the authors' view, preferable if the surgeon has the necessary experience and skills in the field of arthroscopy, especially in the case of difficult and challenging posttraumatic elbow stiffness.

Several limitations apply to this study. The first limitation of the study was the comparably small size and unbalanced sampling of cohorts, which enhances the risk of a type 2 error. Moreover, since the arthroscopic approach is performed predominantly in stiff elbows in the authors' clinic, it is difficult to directly compare the procedures with different groups due to the risk of a patient selection bias and confounding factors. However, since additional confounding surgical factors, like hardware removal or ligament reconstruction, were excluded, the authors are confident that they achieved homogeneous patient cohorts.

\section{Conclusions}

It was possible to compare the clinical short-term results of arthroscopic and open elbow arthrolysis in a prospective study. Good to excellent functional recovery was observed in both cohorts when evaluating improvements in the DASH score, the gain in elbow motion, and the decrease in pain. When comparing the delta values of the groups between the preoperative status and postoperative follow-up, no significant changes were found. This might be due to the comparably small size and unbalanced sampling of the cohorts. Nevertheless, certain tendencies were observed. While the mean gain in elbow motion in the open group reached $36^{\circ}$ after 6 months, the arthroscopic group achieved an increase of $21^{\circ}$. Meanwhile, the decrease in the DASH score and pain was higher in the arthroscopic group. As no neurovascular complications and infections occurred in either group, both procedures must be considered as valid options to treat posttraumatic elbow stiffness. In light of these considerations and the advances in minimally invasive surgical techniques, the arthroscopic approach has evolved to become an essential option and alternative to treat posttraumatic elbow stiffness.

\section{Corresponding address

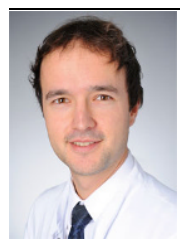 \\ T. Leschinger, M.D. \\ Center for Orthopedic and Trauma Surgery, University Medical Center \\ Kerpenerstr. 62, 50937 Cologne, Ger- many tim.leschinger@uk-koeln.de}

\section{Compliance with ethical guidelines}

Conflict of interest T. Leschinger, M. Hackl, M. Lenz, V. Rausch, L.P. Müller, and K. Wegmann declare that they have no competing interests.

This study has an institutional review board approval from the University of Cologne. All procedures performed in studies involving human participants were in accordance with the ethical standards of the institutional and/or national research committee and with the 1975 Helsinki declaration and its later amendments or comparable ethical standards. Informed consent was obtained from all individual participants included in the study.

Open Access. This article is distributed under the terms of the Creative Commons Attribution 4.0 International License (http://creativecommons.org/licenses/by/ 4.0/), which permits unrestricted use, distribution, and reproduction in any medium, provided you give appropriate credit to the original author(s) and the source, provide a link to the Creative Commons license, and indicate if changes were made. 


\section{Originalarbeit}

\section{References}

1. Cai J, Wang W, Yan H, Sun Y, Chen W, Chen S, Fan C (2015) Complications of open elbow arthrolysis in post-traumatic elbow stiffness: a systematic review. PLoS ONE 10(9):e138547

2. Cefo I, Eygendaal D (2011) Arthroscopic arthrolysis for posttraumatic elbow stiffness. J Shoulder Elbow Surg 20(3):434-439

3. Charalambous CP, Morrey BF (2012) Posttraumatic elbow stiffness. J Bone Joint Surg Am 94(15):1428-1437

4. Hackl M, Lappen S, Burkhart KJ, Leschinger T, Scaal M, Muller LP, Wegmann K (2015) Elbow positioning and joint Insufflation substantially influence median and radial nerve locations. Clin Orthop Relat Res 473(11):3627-3634

5. Hackl M, Wegmann K, Leschinger T, Borda A, LP M (2016) Prospektive 1-Jahres-Ergebnisse der arthroskopischen Arthrolyse des Ellenbogens. Obere Extrem 172:177

6. Kodde IF, van Rijn J, van den Bekerom MP, Eygendaal D (2013) Surgical treatment of posttraumatic elbow stiffness: a systematic review. JShoulder Elbow Surg 22(4):574-580

7. Kwak JM, Kholinne E, Sun Y, Lim S, Koh KH, Jeon IH (2019) Clinical outcome of osteocapsular arthroplasty for primary osteoarthritis of the elbow: comparison of arthroscopic and open procedure. Arthroscopy 35(4):1083-1089

8. LeschingerT, Muller LP, HackIM, Wegmann K (2016) Techniken der Arthrolyse am Ellenbogen. Obere Extrem 11:149-158

9. Lindenhovius AL, Jupiter JB (2007) The posttraumatic stiff elbow: a review of the literature. J Hand Surg Am 32(10):1605-1623

10. Lubiatowski P, Slezak M, Walecka J, Breborowicz M, Romanowski L (2018) Prospective outcomeassessment of arthroscopic arthrolysis for traumatic and degenerative elbow contracture. JShoulder Elbow Surg 27(9):e269-e278

11. Rai S, Zhang $Q$, Tamang $N$, Jin $S$, Wang $H$, Meng C (2019) Arthroscopic arthrolysis of posttraumatic and non-traumatic elbow stiffness offers comparable clinical outcomes. BMC Musculoskelet Disord 20(1):285

12. Willinger $L$, Siebenlist $S$, Lenich $A$, Liska $F$, Imhoff AB, Achtnich A (2018) Arthroscopic arthrolysis provides good clinical outcome in posttraumatic and degenerative elbow stiffness. Knee Surg Sports Traumatol Arthrosc 26(1):312-317

13. Wu X, Wang $H$, Meng C, Yang S, Duan D, Xu W, Liu X, Tang M, Zhao J (2015) Outcomes of arthroscopic arthrolysis for the post-traumatic elbow stiffness. Knee Surg Sports Traumatol Arthrosc 23(9):2715-2720 